\title{
DINÂMICA DA ASSIMILAÇÃo DE MÉTODOS ANALÍTICOS PELA CIÊNCIA NO BRASIL
}

\author{
Uajará Pessoa Araújo* \\ uajara@yahoo.com.br
}

Laíse Ferraz Correia*

laise@dcsa.cefetmg.br

Mozar José de Brito**

mozarjdb@ufla.br

Hudson Fernandes Amaral***

hfamaral@face.ufmg.br

*Centro Federal de Educação Tecnológica de Minas Gerais - Belo Horizonte, MG / Brasil

**Universidade Federal de Lavras - Lavras, MG / Brasil

***Universidade Federal de Minas Gerais - Belo Horizonte, MG / Brasil

http://dx.doi.org/10.1590/1413-2311.1012015.57388

Recebido em 29/07/2015

Aprovado em 20/06/2016

Disponibilizado em 31/08/2016

Avaliado pelo sistema "double blind review"

Revista Eletrônica de Administração

Editora-chefe: Aurora Zen

ISSN 1413-2311 (versão "on line")

Editada pela Escola de Administração da Universidade Federal do Rio Grande do Sul.

Periodicidade: Quadrimestral

Sistema requerido: Adobe Acrobat Reader

\section{RESUMO}

O esforço de pesquisa requer recursos financeiros, que são, em parte, públicos. $\mathrm{O}$ aumento da eficiência no seu uso pode assegurar uma compensação à Sociedade pelo investimento. Daí a relevância de se compreender os mecanismos e as particularidades da pesquisa científica que é desenvolvida, em boa parte, na Academia. Este trabalho teve como finalidade contribuir para o entendimento do processo de difusão de conhecimento no campo científico brasileiro, e em destaque, na Administração, investigando a sua dinâmica a partir da incorporação inicial, seguido de propagação e da consolidação. Para tanto, lançou mão de métodos bibliométricos e sociométricos, acompanhando a evolução da aplicação da Análise Envoltória de Dados (DEA), de largo emprego na pesquisa da eficiência na Administração Pública e em outros setores econômicos - em comparação com a absorção de outras técnicas matemáticas de apoio à decisão e também da própria sociometria. Trata-se de um estudo objetivo, quantitativo, longitudinal, com finalidade descritiva e explicativa. Os principais resultados encontrados foram o modelo de difusão e a quantificação da relevância da pós-graduação stricto sensu na assimilação da DEA, sobressaindo o papel de ligações fortes e da proximidade física e a alavancagem da produtividade acadêmica pela especialização, no caso, 
DINÂMICA DA ASSIMILAÇÃo DE MÉTODOS ANALÍTICOS PELA CIÊNCIA NO

BRASIL

instrumental - situação observada em função do caminho metodológico seguido, distinto de outras pesquisas.

Palavras-chave: Eficiência; Ciência \& Tecnologia, Análise Envoltória de Dados; Difusão.

\title{
DYNAMICS OF THE DIFFUSION PROCESS OF ANALYTICAL TECHNIQUES BY BRAZILIAN SCIENCE
}

\begin{abstract}
The research effort requires financial resources, which are, partly, public. Enhancing the efficiency in the use of public resources could provide some compensation to Society for this kind of investment. For this reason, it is relevant to understand the specific dynamics of academia. This paper aims to contribute to the understanding of the knowledge diffusion process in the Brazilian Scientific field. To carry out the research, we applied bibliometric and sociometric analysis to address the evolution of the data envelopment analysis (DEA) technique, largely applied in the public sector. It consists of an objective, quantitative and, longitudinal study, with descriptive and explanatory purposes. Our main result is the relevance of the master's and doctoral programs for DEA's diffusion. Finding this result was possible due to the methodological path adopted, different from other researches.
\end{abstract}

Key words: Efficiency; Science \& Technology; Data Envelopment Analysis; Diffusion

\section{DINÁMICA DE ASIMILACIÓN DE LOS METODOS ANALÍTICOS DE LA CIENCIA EN BRASIL}

\section{RESUMEN}

El esfuerzo de investigación requiere recursos financieros, que son parte del Estado. Aumento de la eficiencia en su uso puede garantizar una compensación a la Sociedad. De ahí la importancia de la comprensión de los mecanismos y las características de la investigación científica que se desarrolla en gran parte en la Academia. Este trabajo tuvo como objetivo contribuir a la comprensión del proceso de difusión del conocimiento en el ámbito científico brasileño, y destacó en la Administración. Para ello, hizo uso de métodos bibliométricos y sociométricos, siguiendo la evolución de la aplicación del análisis envolvente de datos (DEA), amplio empleo en la búsqueda de la eficiencia en la administración pública y en otros sectores de la economía - en comparación con la absorción de otras técnicas matemáticas apoyo a las decisiones y también el sociometría. Esto es uno estudio cuantitativo, longitudinal, con finalidad descriptiva y explicativa. Los principales resultados fueron el modelo de difusión y cuantificar la importancia de escuelas de posgrado en la asimilación de la DEA, destacando el papel de los lazos fuertes y la proximidad física y aprovechan la productividad académica a través de la especialización en el caso, instrumental - situación observado debido al enfoque metodológico seguido, distinta de otras investigaciones.

Palabras clave: Eficiencia; Ciencia y Tecnología, Análisis Envolvente de Datos; Difusión. 
Uajará Pessoa Araújo, Laíse Ferraz Correia, Mozar José de Brito \& Hudson Fernandes Amaral

\section{INTRODUÇÃO}

No Brasil, o setor público investe historicamente algo próximo a 0,5\% do PIB em Pesquisa e Desenvolvimento (P\&D). Não é um volume desprezível, ainda que insuficiente para atender as demandas da área. É razoável a Sociedade exigir a aplicação eficiente desses recursos, que lhe são deduzidos quando há outras carências. Um requisito para otimizar a relação custo/benefício desses investimentos é a compreensão da dinâmica da pesquisa no ambiente nacional. Esta investigação pretende dar uma contribuição nesse sentido, voltandose ao entendimento do processo de incorporação de novos conhecimentos; partindo da admissão que, tão importante quanto a criação de conhecimento seria a sua transmissão, considerada essencial para o progresso da ciência e para potencializar as oportunidades de geração de produtos ou processos inovadores. O volume considerável de trabalhos voltados ao processo de adoção de inovações é uma indicação da relevância do tema (YU; WANG; YU, 2010; GAO; GUAN, 2012; SRIWANNAWIT; SANDSTRÖM, 2014).

É virtualmente impossível explorar a difusão de todo o conhecimento nas múltiplas áreas de conhecimento, não só pela vastidão a ser coberta, mas também pela complexidade do processo (GAO; GUAN, 2012; SRIWANNAWIT; SANDSTRÖM, 2014). Por isso, a preocupação com o entendimento de padrões de transmissão tem produzido pesquisas particularizadas, como as de Yu, Wang e Yu (2010), cujo objeto foi a difusão da Nanociência; de Gao e Guan (2012), que focou o Hirsch-index; de Bettencourt e outros. (2006), concernente à absorção dos Diagramas de Feynman pelos físicos; e de Tonta e Darvish (2010), que estudaram a difusão da Análise da Semântica Latente.

Seguindo a praxe das pesquisas de mesma natureza, foi necessário escolher um objeto específico para analisar a sua difusão. Aqui, a escolha recaiu sobre uma técnica, a Análise Envoltória de Dados (DEA), assumindo alguns pressupostos, que são: capilaridade interdisciplinar, aplicabilidade à Administração Pública e atual estágio de maturidade. Para comparação, acompanhou-se a incorporação da Sociometria e de outras técnicas de apoio à decisão: Processo Analítico Hierárquico (AHP); Fronteira de Produção Estocástica (SFA); e Multicritério de Apoio à Decisão Construtivista (MCDA-C). Comparou-se, ainda, a difusão da DEA no Brasil frente ao mesmo processo em ambiência internacional.

A DEA é desenvolvida no ambiente da Pesquisa Operacional, ramo da Engenharia de Produção, mas com aplicação atual e geral, com destaque na Administração Pública. Ela é uma técnica multivariável, não paramétrica, de análise de eficiência, que permite comparar dados de entrada e saída e que fornece dados sobre possíveis direções para a melhoria do 


\section{DINÂMICA DA ASSIMILAÇÃO DE MÉTODOS ANALÍTICOS PELA CIÊNCIA NO BRASIL}

status quo das unidades ineficientes. O trabalho de Charnes, Cooper e Rhodes (1978) é apontado como a origem da DEA (ROUSSEAU; ROUSSEAU, 1997), que, hoje, está entre as técnicas de avaliação de eficiência preferidas pelos pesquisadores das áreas de Engenharia e Administração (NASCIMENTO e outros, 2010).

É interessante notar que a DEA já foi objeto de pesquisas cientométricas e utilizada como método para construir indicadores (ROUSSEAU; ROUSSEAU, 1997); para medir o impacto em termos de citações de periódicos da área de Economia (HALKOS; TZEREMES, 2011); e para comparar a eficiência de países quanto à P\&D (SHARMA; THOMAS, 2008). No estudo de Macedo, Casanova e Almeida (2009) sobre a difusão da DEA no Brasil, os resultados sugeriram que: o uso da DEA era embrionário; as publicações ocorriam principalmente no periódico Pesquisa Operacional; os autores estavam concentrados em algumas instituições; e a DEA era aplicada nos setores do agronegócio, bancário, educação, ciência e tecnologia e outros serviços de natureza pública.

Desse arcabouço, emergiu a questão fundamental desta investigação: como tem sido o processo de incorporação da DEA no campo científico brasileiro?

O desenvolvimento da pesquisa, apoiado nas considerações preliminares apresentadas na seção 1 deste artigo, está delineado na seção 2, seguido pelos resultados e discussão que ensejaram as conclusões apresentadas na última seção do texto, junto com as limitações da investigação e a proposição de novos trabalhos.

\section{CONSIDERAÇÕES PRELIMINARES}

A difusão do conhecimento é considerada um processo social. A primeira proposição sugere a transmissão de pessoa a pessoa, guardando, dessa forma, similaridade com a disseminação de doenças infecciosas (BETTENCOURT e outros, 2006; GAO; GUAN, 2012). Nesse modelo, as pessoas adotam um novo comportamento quando elas entram em contato com alguém que já o adotou, implicando, por exemplo, que a inovação disseminar-se-ia rapidamente em redes bem conectadas; e que agentes com maior número de ligações seriam os portais para a difusão.

Em um enfoque alternativo, baseado na teoria dos jogos e no conceito de maximização da utilidade, as pessoas adotariam uma inovação quando um número suficiente de vizinhos já a teriam adotado porque enxergam benefícios associados em seguir o grupo (MONTANARI; SABERI, 2010). 
Uajará Pessoa Araújo, Laíse Ferraz Correia, Mozar José de Brito \& Hudson Fernandes Amaral

Essas proposições têm em comum e como consequência tornar natural a apropriação de métodos desenvolvidos para estudar as redes sociais para alcançar alguma compreensão sobre a dinâmica da disseminação de práticas científicas. Adicionalmente, o modelo que propõe similaridade entre a disseminação do conhecimento e a de doenças infecciosas, implica a adoção, em alguma escala, de construções epidemiológicas.

De tal forma que, na proposição epidêmica, a DEA, tomada como agente etiológico, seria dotada de atributos segundo sua relação com o hospedeiro (pesquisador brasileiro), que seriam importantes para o entendimento de sua disseminação: infectividade, capacidade da DEA de penetrar, se desenvolver e/ou se multiplicar em um ou outro pesquisador ocasionando uma infecção (estaria ligada a compatibilidade de seu uso e a facilidade de sua assimilação); patogenicidade, capacidade da DEA, uma vez assimilada, de produzir sintomas e sinais (no caso, levar o pesquisador a produzir trabalhos aplicando a DEA); virulência, capacidade da DEA de produzir efeitos de grande magnitude, no caso tornar a produção do pesquisador dependente da DEA em uma extensão significativa; e imunogenicidade, capacidade da DEA, de, após a infecção, induzir a imunidade no pesquisador, quando ela poderia ser abandonada o pesquisador encontraria outra técnica que lhe pareça mais adequada.

Nessa proposição, o pesquisador estaria sujeito a alguns determinantes (parâmetros que, em sua articulação e sinergia, propiciariam a atuação do estímulo de adoção da DEA), tais como, a aproximação da área científica de sua atuação com o estudo de eficiência e as características do seu círculo de relacionamento científico, que o levaria ou não, a se transformar em um "reservatório" pronto a contaminar um "hospedeiro susceptível", em função da sua maior ou menor resistência (capacidade de assimilação da base matemática e/ou acesso a software; o fato de estar ou não disponível para se dedicar a DEA), imunidade prévia (já usar outro instrumento assemelhado) e fragilidade (depender dos desígnios de um orientador) à incorporação da DEA.

Restaria listar os vetores ou os veículos de contágio. Neles, estariam incluídas peças científicas publicadas, seminários e cursos de treinamento na técnica, orientações de monografias e coautorias com parceiros reservatórios. Os dois últimos induzem contato mais próximo, reservatório-hospedeiro susceptível, considerado relevante nesta investigação.

Haveria consistência entre as metáforas epidemiológicas e as proposições de Roger (1983): uma técnica seria mais fácil e rapidamente difundida se for percebida como vantajosa; se houver compatibilidade com o conhecimento, valores e experiências já incorporados; se for de fácil entendimento e uso, mesmo a partir de uma base incipiente; e se propiciar evidências imediatas de visibilidade. 
DINÂMICA DA ASSIMILAÇÃO DE MÉTODOS ANALÍTICOS PELA CIÊNCIA NO

\section{BRASIL}

O padrão de difusão da DEA consistiria de uma curva em "S" de novos adotantes ao longo do tempo, em que, primeiramente, alguns poucos adotam a técnica e, em seguida, o número de praticantes aumenta rapidamente. Seria a fase de nucleação, em que deve ser atingida a massa crítica (número suficiente de praticantes capazes de sustentar o processo) indo desde o início da propagação até a primeira curvatura do "S". Depois, o número de adotantes continuaria a crescer, mas a taxa de adoção diminuiria, com cada vez menos novos adeptos. Esse processo se arrastaria lentamente até seu encerramento (Gao e Guan, 2012).

\subsection{Elementos sociométricos}

Há certo consenso de que as redes interpessoais são importantes para explicar os padrões de difusão de conhecimento, assim como qualquer outra inovação, pois "it is as unthinkable to study diffusion without some knowledge of the social structures in which potential adopters are located as it is to study blood circulation without adequate knowledge of the structure of veins and arteries" (KATZ, 1961, p.16).

Para alguns pesquisadores, como Gao e Guan (2012), o modelo de difusão requer que um praticante dissemine a técnica para os seus contatos. Admite-se que a probabilidade de uma pessoa adotar a técnica seja proporcional ao grau de sua exposição, ou seja, à fração de praticantes entre os seus contados. Essa fração, atingindo um limite pessoal, próprio de cada pesquisador, leva-o a adotar a técnica e a infectar outros.

As citações de autores são utilizadas - por exemplo, Yu, Wang e Yu (2010) e Gao e Guan (2012) - como indicativo das relações entre os cientistas, permitindo a construção de sociogramas e a apuração de parâmetros derivados do posicionamento do agente na estrutura. O pressuposto desses trabalhos é de que as citações de pesquisas anteriores indicam a sua difusão. O sistema de citação atuaria como elemento de consubstanciação das ligações, servindo para a canalização do conhecimento.

Contudo, nesta pesquisa o indicativo escolhido foi a coautoria, que sugere uma relação mais próxima entre os pesquisadores quando comparada às citações, em que a proximidade entre o autor citado e o autor do texto em consideração pode ser tão-somente a conferida pelo texto. Embora a utilização de coautorias como indicador de ligações entre pesquisadores seja menos frequente, alguns trabalhos as empregaram, por exemplo: Tonta e Darvish (2010), Glänzel (2002) e Ho e Liu (2013). 
Uajará Pessoa Araújo, Laíse Ferraz Correia, Mozar José de Brito \& Hudson Fernandes Amaral

\subsection{Difusão em escala internacional}

Ho e Liu (2013) estudaram a difusão da DEA entre regiões por meio de artigos publicados de 1978 a 2011, recuperados da Web of Science. Eles aplicaram a sociometria das relações de coautorias e exploraram a localização, as áreas de pesquisa e as interligações da rede que apresentou maior diâmetro. Eles propuseram a decomposição do processo em duas fases: a primeira, mais lenta, até 2000; a segunda, a partir daí, mais acelerada, com seu ponto médio em 2012, e - expectativa inferida dos dados - início da segunda curva do S do modelo logístico para algum ponto a partir de 2015, com redução do número de novos artigos. A razão para a ruptura em 2002 seria, supostamente, a facilitação representada pelo surgimento de softwares para aplicação da DEA, removendo dificuldades da programação linear.

Outras conclusões de Ho e Liu (2013) foram: (1) a proximidade geográfica é importante na cooperação; (2) as conexões pessoais em vários campos científicos encorajam a difusão; (3) os pesquisadores de maior senioridade, com trabalhos de maior impacto e, menos importante, com maior número de ligações distintas, se envolvem mais na coordenação de recursos, absorvendo e difundindo o conhecimento em locais diferentes - ainda que esse último ponto seja passível de discussão em função dos resultados de Delre e outros (2010) os quais sugerem ser superestimado o poder de influência das pessoas de destaque, com muitas ligações, na adoção de inovações.

\section{MÉTODO}

Este trabalho recorreu a um conjunto de métodos com ênfase na bibliometria e na sociometria das ligações entre pesquisadores, já consolidados no estudo do desenvolvimento da ciência, como defendido no trabalho de Bettencourt e outros (2006). Tal opção imprimiu um caráter quantitativo à investigação, com encaminhamento estatístico consoante com o propósito predominantemente descritivo da pesquisa.

\subsection{Coleta de dados}

Pela teoria do mundo pequeno, popularizada a partir de Travers e Milgram (1967), as pessoas estariam conectadas entre si em uma rede incomensurável para efeitos práticos. Isso implica a necessidade de uma delimitação, ainda que arbitrária, tornando uma parte desse 


\section{DINÂMICA DA ASSIMILAÇÃO DE MÉTODOS ANALÍTICOS PELA CIÊNCIA NO BRASIL}

universo compreensível. Em decorrência, o processo de levantamento de dados aqui adotado seguiu as disposições apresentadas a seguir.

A unidade de dados foram teses, dissertações e artigos (esses, publicados em periódicos), obtidos de repositórios virtuais e tendo como autores pesquisadores brasileiros ou radicados no Brasil que lidaram empiricamente com a DEA ou contribuíram para o seu aperfeiçoamento. Essa primeira definição implicou a exclusão de trabalhos não disponíveis na internet, publicações em anais, monografias de conclusão de curso de graduação e de especialização, livros e outros materiais, e aqueles que se ocupam da DEA em revisões de literatura.

Para recuperar os dados, optou-se por repositórios e buscadores utilizados em outras pesquisas de mesmo gênero: Web of Science, Biblioteca Digital Brasileira de Teses e Dissertações (BDTD), Google Acadêmico, Scientific Electronic Library Online (SciELO) e Scientific Periodicals Electronic Library (SPELL). Por praticidade, foram consideradas, mas descartadas, as seguintes ações: (1) pesquisar os bancos de teses de cada um dos 344 cursos de pós-graduação stricto sensu das áreas Administração, Contabilidade e Turismo; Economia; e Engenharia de Produção, que se mostraram como aquelas que concentram as pesquisas com DEA; (2) pesquisar nos sites de cada um dos periódicos daquelas áreas; (3) pesquisar a produção de cada um dos 986 pesquisadores apontados pela Plataforma Lattes como relacionados à DEA; e (4) adotar o método Snow Ball, que consiste em pré-selecionar alguns artigos e descobrir os demais, por meio das referências desses artigos e daí, as referências das referências.

As consultas se entenderam de 16.10 a 15.11.2014. Na Web of Science foram encontrados 195 trabalhos. No Google Acadêmico, 2.840. No BDTD, 158. No SciELO, 59. E, no SPELL, 30 trabalhos. Cada item foi analisado e, atendendo aos critérios estabelecidos, baixados e catalogados. Ao final, foram selecionados 487 artigos, 240 dissertações, 75 teses e 1 pesquisa de livre docência, total de 803 itens. A diferença entre itens investigados e itens selecionados foi devido ao não atendimento dos critérios de pesquisa e à duplicidade de registros.

Comparado com outros trabalhos de mesma matriz, por exemplo, Nascimento e outros (2010), Gao e Guan (2012), Tonta e Darvish (2010), Macedo, Casa Nova e Almeida (2009), a amostra que compôs o Banco de Dados I (BD.I) tem tamanho aceitável. Mesmo que não seja possível lhe conceder o status de aleatoriedade estrita, a amostra foi constituída sem a interferência dos responsáveis pela pesquisa, além de seguir o seu protocolo, dando iguais chances aos trabalhos de participar, dependendo apenas das capacidades e algoritmos dos 
Uajará Pessoa Araújo, Laíse Ferraz Correia, Mozar José de Brito \& Hudson Fernandes Amaral

buscadores empregados. Justamente para preservar essa característica, optou-se por não empregar o repositório "Banco de Teses Capes", uma vez que ele dispunha somente de trabalhos dos anos de 2011 e 2012, o que causaria um viés temporal indesejável.

Para testar o alcance da amostra, foram sorteados do BD.I trinta de seus artigos dos últimos cinco anos e computados a frequência com que as referências desses artigos, aderentes aos critérios preestabelecidos, estavam contidos no BD.I. Das 102 referências testadas, 77 faziam parte da amostra. Teses e dissertações antigas representaram a maior parte dos itens ausentes. Daí propõe-se que o indicador de $76 \%$ seja admitido como o grau de completeza da seleção, no geral. Contudo, exclusivamente para as teses e dissertações, o grau de completeza seria menor. Isso porque o Banco de Teses da Capes conta com 93 trabalhos com DEA, frente aos 66 do BD.I, ambos para 2011 e 2012, o que representa $71 \%$.

\subsection{Tratamento e análise de dados}

O BD.I foi criado na plataforma SPSS, recebendo o nome da produção e de seus autores, ano de publicação, tipo de trabalho (artigo, dissertação ou tese), periódico e sua melhor classificação pelo Qualis (para artigos), área de concentração e universidade da defesa (para teses e dissertações) e classe do objeto em estudo, essa de acordo com a Classificação Nacional de Atividades Econômicas (CNAE) - Versão 2.0. Adicionalmente, foi identificado se o título continha menção à DEA. Daí, foram aplicados estatísticas descritivas e testes de agrupamentos e de adequação aos modelos estatísticos.

As relações sociométricas foram obtidas mediante os softwares Pajek e Ucinet. Neles, foram tomados como uma pseudo-relação de autoria o conjunto formado pelo aluno e pelo(s) orientador(es) do trabalho, complementando as relações de coautorias efetivas dos artigos.

Nota: Como a pesquisa não envolveu experimentação ou outro procedimento evasivo em pessoas, no campo da ética em pesquisas ela não avançou além da preocupação com a sua integridade e objetividade.

\section{RESULTADOS}

A Tabela 1 e a Figura 1 retratam a fração acumulada amortecida (média móvel de três anos, considerado como o hiato para conceber, desenvolver e publicar a pesquisa) de trabalhos de DEA na forma de artigos em periódicos (DEA-A), de teses ou dissertações (DEA-T) e combinados: artigos, teses e dissertações (DEA-AT). Adicionalmente, com o fito 
DINÂMICA DA ASSIMILAÇÃO DE MÉTODOS ANALÍTICOS PELA CIÊNCIA NO

\section{BRASIL}

de suprir elementos para comparação, são apresentados os dados relativos aos trabalhos (volume total, sem exclusões, mesmo de repetições) recuperados do Google Acadêmico (DEA-G), e, da mesma forma, também do Google Acadêmico: Processo Analítico Hierárquico (AHP-G), Análise Fronteira Estocástica (SFA-G), Modelo Multicritério de Apoio à Decisão Construtivista (MCDA-G), Sociometria aplicada em Capital Social (SOC-A-G), em Redes de Empresas (SOC-B-G) e em Bibliometria (SOC-C-G) e DEA recuperado da Web of Science, artigos EUA (DEA-W).

No segundo bloco de linhas da Tabela 1 estão a quantidade de itens recepcionados na pesquisa. E, ao final dessa Tabela, é apresentado o teste de ajuste dos dados ao modelo cúbico $\left(\right.$ do tipo: $\mathrm{At}^{3}+\mathrm{Bt}^{2}+\mathrm{Ct}+\mathrm{D}$, em que $\mathrm{t}=$ ano, da seguinte forma: $1996=1,1997=2 \ldots 2013=$ 18), resultado de computação pelo software SPSS. A curva de cada variável é oferecidanos gráficos da Figura 1.

Os dados indicam que: (a) os instrumentos de apoio à decisão (DEA, AHP, MDCAConstrutivista) passaram a ser utilizados de forma mais sistemática na pesquisa brasileira a partir de 2000-2002, depois de alguns trabalhos pioneiros - no caso da DEA, no meio da década de 1990; (b) as curvas de DEA relativas a trabalhos brasileiros têm, entre si, uma aproximação apreciável, o que também poderia ser tomado como indicativo de consistência dos métodos de recuperação do material; (c) as curvas dos instrumentos de apoio à decisão, no Brasil, apresentam uma apreciável aproximação entre si, destacando o delay do MDCAConstrutivista; (d) as curvas dos instrumentos de apoio à decisão se aproximam das curvas relativas à Sociometria; (e) a produção de peças científicas usando DEA, após período de oscilações mais significativas (entre 1996 e 2002, relacionado com o volume ainda reduzido de trabalhos no período), permaneceu crescente, mas à taxa de crescimento cada vez menor inferior a $+20 \%$ sobre o ano precedente. Continuando a tendência, seria razoável admitir que a produção se estabilizará (ou mesmo diminuirá) em algum ponto do futuro, a menos de alguma ocorrência não previsível; e (f) o Modelo Cúbico sobreviveu aos testes a que foi submetido, ressaltando que, em alguns casos, apurou-se para o coeficiente A da fórmula o valor zero, reduzindo-a a uma expressão do segundo grau, resultando em um trecho de parábola.

Tabela 1 - Incorporação de instrumentos analíticos na ciência brasileira

\begin{tabular}{cccccccccccccc}
\hline & ANO & $\begin{array}{c}\text { DEA- } \\
\text { A }\end{array}$ & $\begin{array}{c}\text { DEA } \\
-\mathrm{T}\end{array}$ & $\begin{array}{c}\text { DEA } \\
- \text { AT }\end{array}$ & $\begin{array}{c}\text { DEA } \\
-\mathrm{G}\end{array}$ & $\begin{array}{c}\text { AHP- } \\
\mathrm{G}\end{array}$ & $\begin{array}{c}\text { SFA- } \\
\text { G }\end{array}$ & $\begin{array}{c}\text { MCDA- } \\
\text { G }\end{array}$ & $\begin{array}{c}\text { SOC- } \\
\text { A-G }\end{array}$ & $\begin{array}{c}\text { SOC- } \\
\text { B-G }\end{array}$ & $\begin{array}{c}\text { SOC- } \\
\text { C-G }\end{array}$ & $\begin{array}{c}\text { DEA- } \\
\text { W }\end{array}$ \\
\hline $5 !$ & 1996 & 0,00 & 0,00 & 0,00 & 0,00 & 0,00 & 0,00 & 0,00 & 0,00 & 0,00 & 0,00 & 0,04 \\
\hline
\end{tabular}


Uajará Pessoa Araújo, Laíse Ferraz Correia, Mozar José de Brito \& Hudson Fernandes Amaral

\begin{tabular}{|c|c|c|c|c|c|c|c|c|c|c|c|c|}
\hline & 1997 & 0,00 & 0,01 & 0,01 & 0,00 & 0,00 & 0,00 & 0,00 & 0,00 & 0,00 & 0,01 & 0,09 \\
\hline & 1998 & 0,01 & 0,02 & 0,01 & 0,00 & 0,01 & 0,01 & 0,00 & 0,00 & 0,00 & 0,01 & 0,14 \\
\hline & 1999 & 0,02 & 0,03 & 0,02 & 0,01 & 0,01 & 0,01 & 0,00 & 0,00 & 0,00 & 0,01 & 0,18 \\
\hline & 2000 & 0,02 & 0,04 & 0,03 & 0,01 & 0,02 & 0,02 & 0,00 & 0,01 & 0,00 & 0,01 & 0,23 \\
\hline & 2001 & 0,03 & 0,06 & 0,04 & 0,02 & 0,03 & 0,03 & 0,00 & 0,01 & 0,00 & 0,01 & 0,26 \\
\hline & 2002 & 0,05 & 0,09 & 0,07 & 0,03 & 0,05 & 0,05 & 0,00 & 0,02 & 0,01 & 0,01 & 0,30 \\
\hline & 2003 & 0,08 & 0,13 & 0,10 & 0,06 & 0,07 & 0,08 & 0,01 & 0,03 & 0,02 & 0,01 & 0,34 \\
\hline & 2004 & 0,12 & 0,17 & 0,14 & 0,10 & 0,11 & 0,13 & 0,01 & 0,04 & 0,03 & 0,02 & 0,39 \\
\hline & 2005 & 0,17 & 0,21 & 0,19 & 0,15 & 0,14 & 0,18 & 0,04 & 0,07 & 0,05 & 0,02 & 0,43 \\
\hline & 2006 & 0,23 & 0,27 & 0,25 & 0,21 & 0,19 & 0,25 & 0,08 & 0,11 & 0,09 & 0,04 & 0,48 \\
\hline & 2007 & 0,29 & 0,34 & 0,31 & 0,28 & 0,26 & 0,33 & 0,14 & 0,17 & 0,14 & 0,08 & 0,53 \\
\hline & 2008 & 0,36 & 0,42 & 0,39 & 0,36 & 0,34 & 0,42 & 0,22 & 0,25 & 0,20 & 0,14 & 0,59 \\
\hline & 2009 & 0,44 & 0,51 & 0,47 & 0,46 & 0,43 & 0,50 & 0,31 & 0,35 & 0,29 & 0,21 & 0,66 \\
\hline & 2010 & 0,54 & 0,64 & 0,58 & 0,57 & 0,55 & 0,61 & 0,43 & 0,48 & 0,42 & 0,32 & 0,73 \\
\hline & 2011 & 0,67 & 0,76 & 0,71 & 0,70 & 0,68 & 0,72 & 0,57 & 0,63 & 0,58 & 0,48 & 0,82 \\
\hline & 2012 & 0,83 & 0,89 & 0,85 & 0,84 & 0,83 & 0,86 & 0,76 & 0,81 & 0,77 & 0,70 & 0,91 \\
\hline & 2013 & 1,00 & 1,00 & 1,00 & 1,00 & 1,00 & 1,00 & 1,00 & 1,00 & 1,00 & 1,00 & 1,00 \\
\hline & 2014 & - & - & - & - & - & - & - & - & - & - & - \\
\hline \multirow{3}{*}{$\mathrm{N}$} & Até 2013 & 427 & 304 & 731 & 2471 & 1564 & 575 & 382 & 936 & 816 & 566 & 1348 \\
\hline & Em 2014 & 60 & 12 & 72 & 271 & 147 & 66 & 41 & 106 & 107 & 100 & 82 \\
\hline & Total & 487 & 316 & 803 & 2742 & 1711 & 641 & 423 & 1042 & 923 & 666 & 1430 \\
\hline \multicolumn{2}{|c|}{$\mathrm{R}^{2}$ ajustado } & 0,999 & 0,999 & 1,000 & 1,000 & 1,000 & 0,999 & 0,999 & 1,000 & 0,999 & 0,993 & 1,000 \\
\hline \multicolumn{2}{|c|}{ E P Estimativa } & 0,010 & 0,011 & 0,005 & 0,005 & 0,004 & 0,008 & 0,008 & 0,007 & 0,011 & 0,024 & 0,004 \\
\hline \multicolumn{2}{|c|}{$\begin{array}{l}\text { Sig. } \\
\text { (ANOVA) }\end{array}$} & 0,000 & 0,000 & 0,000 & 0,000 & 0,000 & 0,000 & 0,000 & 0,000 & 0,000 & 0,000 & 0,000 \\
\hline
\end{tabular}

Nota: 2014, até começo de novembro, E. P. = Erro Padrão. 
DINÂMICA DA ASSIMILAÇÃO DE MÉTODOS ANALÍTICOS PELA CIÊNCIA NO

\section{BRASIL}

Figura 1 - Ajuste cúbico, com círculos indicando valores observados e linha indicando a curva de ajuste

BD.I
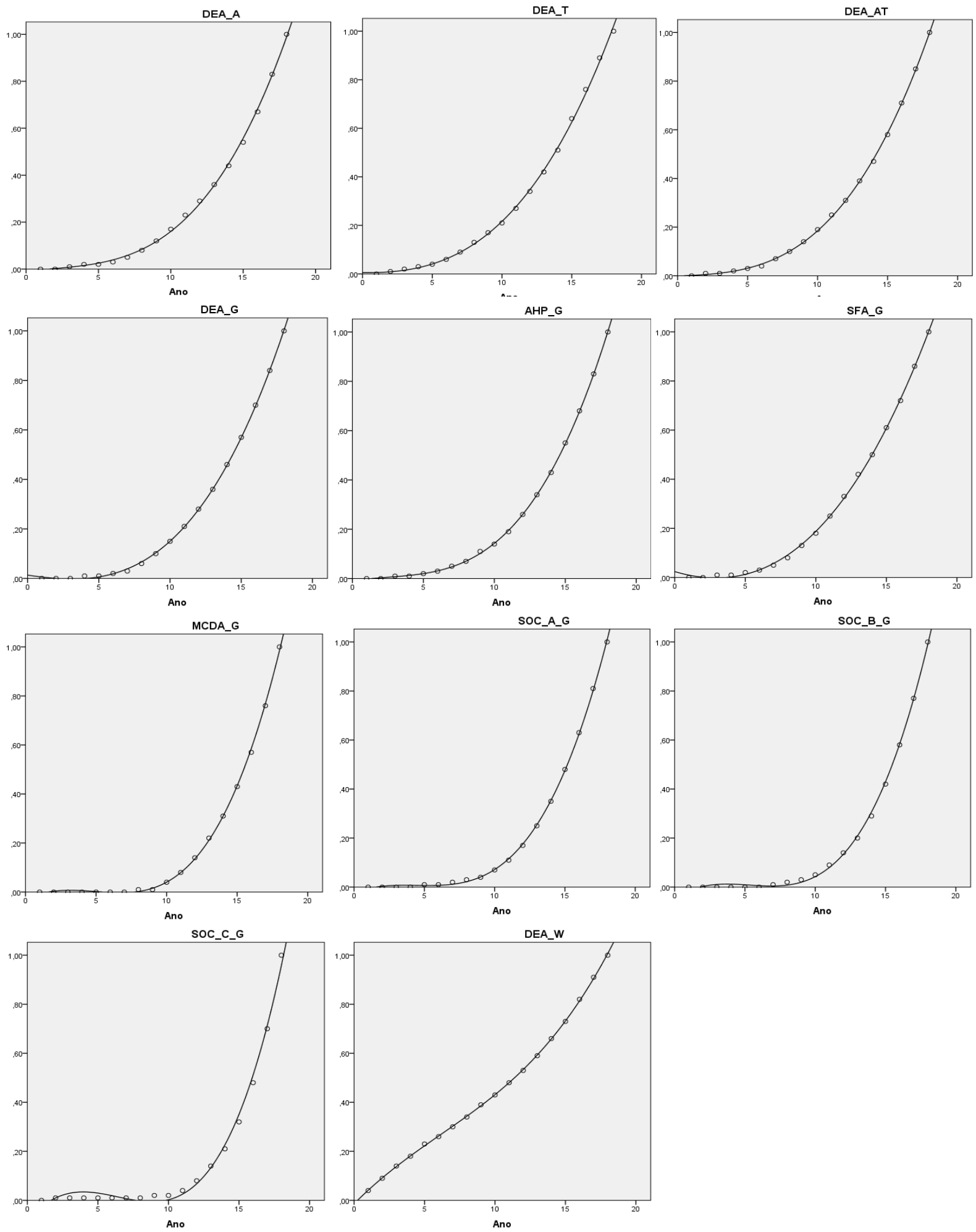

Fonte: dados da pesquisa

Nota: Os círculos indicam os valores observados e a linha, a curva de ajuste - BD.I. 
Uajará Pessoa Araújo, Laíse Ferraz Correia, Mozar José de Brito \& Hudson Fernandes Amaral

\subsection{Aplicação}

A CNAE 2.0 oferece 21 seções para enquadramento das atividades econômicas. Descontando dos 803 trabalhos do BD.I aqueles 62 voltados exclusivamente para desenvolvimento da própria DEA e admitindo múltipla classificação - por exemplo: hospitalescola público, nas seções Educação, Saúde e Administração Pública - comprova-se que a DEA alcançou quase todos os setores.

Contudo, a preferência está em: Administração Pública, Defesa e Seguridade Social, 28,6\% dos trabalhos; Educação, 11,7\%; Agricultura, Pecuária, Produção Florestal, Pesca e Aquicultura, 10,5\%; Saúde Humana e Serviços Sociais, 9,3\%; Atividades Financeiras, de Seguros e Serviços Relacionados, 7,8\%; Transporte, Armazenagem e Correio, 7,6\%; Atividades Profissionais, Científicas e Técnicas, 6,8\%; Indústrias de Transformação, 4,4\%; e Eletricidade e Gás, $4,1 \%$.

Destaca-se a aplicabilidade da DEA na Administração Pública, consonante com a preocupação da Sociedade com a eficiência da burocracia estatal e das Políticas Públicas. Em posição oposta, está o setor industrial: não se tem produzido muitos trabalhos com as empresas dessas áreas.

\subsection{Caracterização dos artigos, teses e dissertações}

Para análise dos 487 artigos do BD.I, foi feita uma divisão temporal arbitrária, agrupando-os em três fases: Fase I (artigos publicados até 2007, inclusive, com um total de 130 artigos); Fase II (de 2008 a 2011, 161 artigos) e Fase III (de 2012 até o final da coleta de dados na metade de novembro de 2014, 178 artigos).

Inicialmente, considerou-se utilizar o impacto do trabalho, medido pelo número de suas citações, como proxy da sua qualidade. Contudo, isso conduziria a um viés temporal, favorável aos trabalhos mais antigos e, daí, esse indicativo foi relegado. Em seu lugar, admitiu-se a classificação por meio do Qualis do periódico que veiculou o artigo como proxy da qualidade (ou do prestígio) da produção. Para tanto, como os periódicos podem receber classificação de mais de uma área, adotou-se como padrão a classe superior entre aquelas indicadas pelas Áreas de Avaliação.

Por último, adotou-se arbitrariamente os pesos utilizados pela Área: Administração, Contabilidade e Turismo para a construção de uma variável de qualidade, da forma: artigo 
DINÂMICA DA ASSIMILAÇÃO DE MÉTODOS ANALÍTICOS PELA CIÊNCIA NO

\section{BRASIL}

publicados em periódicos de classificação $\mathrm{A} 1=100$ pontos, $\mathrm{A} 2=80, \mathrm{~B} 1=60, \mathrm{~B} 2=50, \mathrm{~B} 3=$ 30, B4 = 20, B5 = 10 e C, assim como aqueles não classificados no Qualis, zero ponto.

Os 487 artigos do BD.1 foram publicados em 208 periódicos, 12 dos quais não classificados no Qualis. A distribuição dos artigos foi observada na seguinte ordem: A1 = 28 artigos, A2 = 119, B1 = 99, B2 = 113, B3 = 41, B4 = 23, B5 = 43 e $(C+$ Não classificado $)=$ 21. Dessa forma, seriam distribuídos 26.030 pontos (sem computar a multiautoria), com média de 53,4 pontos por artigo, o que seria equivalente a um conceito entre B1 e B2, indicador de uma produção média bem avaliada, o que sugere que trabalhos utilizando DEA obtiveram boa aceitação nos veículos mais qualificados.

Ao longo das fases, houve um pequeno decréscimo da pontuação média $(56,9 ; 55,9$ e 49,1 - com Sig. do teste Anova = 0,012). Isso foi devido à maior frequência de artigos publicados em veículos não classificados pelo Qualis na última fase.

Outro desdobramento temporal observável diz respeito à menção de DEA no título do artigo. Significativamente (ao nível de tau-c de Kendall de 0,04), houve um aumento da relação "SEM DEA: COM DEA" próxima de 1:1 para 2:1 das duas primeiras fases para a fase III o que, possivelmente, indica que os autores teriam percebido certa saturação de DEA e passaram a dar mais ênfase ao objeto do que ao instrumento aplicado ao estudo.

No que se refere à frequência de distribuição de artigos por periódicos, houve concentração: $50 \%$ dos artigos foram publicados em 30 dos periódicos (total de 208 na amostra e um volume da ordem de milhares, de difícil quantificação, quando são considerados apenas os periódicos voltados para as áreas de Administração, Engenharia de Produção e Economia, classificados ou não pelo Qualis, passíveis de veicular trabalhos sobre a DEA).

Os periódicos mais populares entre os Deamistas - pesquisadores que empregaram essa técnica - foram: Pesquisa Operacional (Qualis A2), com 40 artigos; Relatórios de Pesquisa em Engenharia de Produção da UFF (B5), 16; Produção (B1), 16; Journal of Transport Literature (B2), 12; Organizações Rurais\&Agroindustriais (B1), 12; Engevista (B2), 10; Investigação Operacional (B2), 10; Economia Aplicada (B1), 10; Revista Administração Contemporânea (A2), 9; Gestão \& Produção (A2), 9; Revista Economia e Sociologia Rural (A2), 8; Revista Administração Pública (A2), 8; Revista Brasileira de Economia (A2), 7; e Revista Saúde Pública (A1), 7 artigos.

Como complemento, observa-se que os artigos tenderam a ter múltipla autoria, uma vez que o número de trabalhos com um autor foi de apenas 34 (7\% do total). Excluindo três artigos, que tiveram 7, 8 e 9 autores, que poderiam ser considerados outliers, a média de autores por trabalho foi de 2,90. 
Uajará Pessoa Araújo, Laíse Ferraz Correia, Mozar José de Brito \& Hudson Fernandes Amaral

Já as 240 dissertações, 75 teses e uma monografia de livre docência estão concentradas nas pós-graduações de: Economia, 85 trabalhos; Engenharia de Produção, 73; Administração, 68; Contabilidade, 17; e Turismo, 2. Os demais 71 trabalhos estão dispersos em diferentes áreas, como: Engenharias (outras), Método Numérico Aplicado à Engenharia, Biometria, Educação, Transporte, Zootecnia e mesmo Medicina. O grupo destacado responde, portanto, por $78 \%$ das teses e dissertações recuperadas na pesquisa. As defesas se deram em 56 instituições. As dez primeiras (UFSC e USP, ambas com 32 trabalhos; UFV e UnB, 23; UFPE, 21; UFRJ, 18; UFRGS, 14; UFC, 13; ITA, 12; e UFRN, com 11) respondem por 63\% dos trabalhos dessa natureza no BD.I.

A concentração é significantemente maior quando se considera a existências de vários cursos de todas as áreas citadas sem representação na amostra. Essa situação é melhor exemplificada quando se trata apenas as áreas de maior concentração (Administração, Contabilidade e Turismo, Engenharia de Produção e Economia). Existem no Brasil 344 cursos de mestrado e doutorado nessas áreas, mas 245 deles não estão presentes na amostra, que destaca: Doutorado em Engenharia de Produção da UFSC, 14 teses; Mestrado em Economia da UFPE, 11 dissertações; Mestrado em Engenharia de Produção da UFSC, 10; Mestrado em Administração da UFV, 8; Mestrado em Economia da UnB, 8; Mestrado em Administração da UFRGS, 7; Mestrado em Economia da UFC, 7; Mestrado em Economia da UFV, 7 e Mestrado em Engenharia de Produção da UFF, 7 dissertações.

No que diz respeito à presença de DEA no título das dissertações e teses, por Fase (Fase I, até 2008, 112 trabalhos; Fase II, de 2009-2011, 131; e Fase III, desde 2012, 73), não há diferença estatística significativa. A relação entre "SEM DEA: COM DEA" ficou entre 1,2 e 1,4: 1,0 para as três fases, próxima à relação média para os artigos.

\subsection{DEA e bolsa de produtividade}

Uma aproximação do problema resultou em uma caracterização julgada interessante de quem são os pesquisadores que lidam com a DEA no País, por simplificação, aqui tratados como "Deamistas".

Em 01.11.2014, de 986 currículos de Deamistas cadastrados na Plataforma Lattes, 498 eram doutores (379 participantes de grupos de pesquisa), 343 mestres, 108 graduados com ou sem especialização e 37 não graduados. Tomando apenas os doutores, os Deamistas compõem um pequeno grupo frente ao universo de 210.775 (127.196 em grupos de pesquisa) doutores cadastrados nessa Plataforma. Os maiores quantitativos de doutores Deamistas foram 
DINÂMICA DA ASSIMILAÇÃO DE MÉTODOS ANALÍTICOS PELA CIÊNCIA NO

\section{BRASIL}

encontrados em grupos de pesquisa nas áreas de Engenharia de Produção (140 pesquisadores); Administração, Contabilidade e Turismo (138) e Economia (104), indicando que a DEA é uma ferramenta de maior atrativo para especialistas dessas áreas.

Quando se analisa a relação de doutores cadastrados em grupos de pesquisa e dotados de bolsa de produtividade do CNPq (admitido como proxy de excelência em pesquisa) de Deamistas frente ao total geral de doutores em grupos de pesquisa, também bolsistas, a relação é de 1 bolsa para cada 4,7 doutor-Deamista; frente a 1 bolsa para 8,8 doutores, no geral. São 81 bolsas para 379 doutores-deamistas em grupos de pesquisa.

Propõe-se que existem duas explicações concorrentes para a situação encontrada. A primeira, aplicar DEA alavanca o volume de produção científica (que parece ser o caso para uma pequena fração de Deamistas). A segunda, o pesquisador de maior excelência na pesquisa se sentiria mais atraído e/ou teve maiores oportunidades para adotar a ferramenta.

\subsection{Caracterização dos autores e de sua rede}

Ao analisar a distribuição do número de itens produzidos por pesquisador, constatouse que são poucos os pesquisadores com elevado número de trabalhos (no caso, destacam-se 5 , com 75, 50, 41, 40 e 31) e muitos outros (821) com apenas um trabalho, em um total de 1.132 autores em 2.111 participações. Deve-se lembrar que foi concedido o status de coautor aos orientadores e co-orientadores de teses e dissertações.

Pela distribuição do quadrado inverso de Lotka (1926), frequentemente observada em estudos bibliométricos, mesmo no Brasil, conquanto ajustado (Alvarado, 2002), o número de autores com $n$ contribuições em um campo científico se aproximaria de $1 / n^{2}$ daqueles que fazem uma só contribuição, e que esses, de uma única contribuição seriam algo em torno de $60 \%$ do total de autores. A "Lei" de Lotka seria um caso particular do modelo de potência (ou de poder, power law) inversa, em que $\mathrm{p}(\mathrm{x})=\mathrm{C} \mathrm{x}^{-\alpha}$ para $\mathrm{x}>\mathrm{x}_{\min } \mathrm{e} \alpha>1$. Os valores previstos de acordo com Lotka e os observados foram encontrados correlacionados, com $\mathrm{R}^{2}$ ajustado $=$ 0,995, Erro padrão da estimativa $=11,846$ e sig. $=0,000$, o que implicou a não rejeição do modelo. Na distribuição com valores observados, a fração de autores com uma única contribuição foi de $72 \%$, superior ao sugerido por Lotka.

Foi apurada a pontuação por autor de artigo publicado em periódico (ponderada pela equivalência da Área Administração para a maior avaliação Qualis daquele periódico, admitindo pontuação total por pesquisador independentemente do número de coautorias no artigo). Revela-se que foram distribuídos 75.590 pontos para 756 autores, com notável 
Uajará Pessoa Araújo, Laíse Ferraz Correia, Mozar José de Brito \& Hudson Fernandes Amaral

dispersão de valores. Exemplificando, 37 autores, que publicaram em periódicos Qualis C ou não classificados pelo Qualis, ficaram com zero ponto; enquanto o autor mais contemplado recebeu destacados 3.380 pontos, seguido de outros com 2.800, 2.090, 1.830 (dois pesquisadores) e 1.050 pontos.

Adicionalmente, para caracterização dos pesquisadores que lançaram mão da DEA, foi utilizada a Plataforma Lattes, focando naqueles com quatro ou mais trabalhos (grupo de 91 pesquisadores, compondo uma subamostra de 8\%), que responderam por 791 das 2.111 participações (37\% desse conjunto), considerados como "DEAMISTAS" (em maiúsculas, para diferenciar de "Deamistas") e que constituíram o Banco de Dados II (BD.II).

Os DEAMISTAS foram encontrados distribuídos em 44 instituições, com notável concentração na UFRJ (10 pesquisadores); UFV e USP (7, cada); Embrapa, UFSC e UnB (4, cada), UFF, UFPE, UFRGS e UFRRJ (com 3 DEAMISTAS, cada).

Dos 91 DEAMISTAS, 12 eram mestres, a maioria dos quais em processo de doutoramento. Dos 79 DEAMISTAS-Doutores, 31 detinham bolsa de produtividade em pesquisa do CNPq (portanto, 1 bolsa a cada 2,5 doutor - proporção essa superior à indicada na seção 3.3, para os Deamistas em geral); 26 tinham o pós-doutorado e 56 defenderam seu título há mais de 10 anos. Trata-se, assim, de um grupo qualificado, experiente e que trabalha em instituições de prestígio.

Considerando a sua maior titulação, os DEAMISTAS estão distribuídos nas áreas: Engenharia (40, dentre os quais 28 são da Engenharia de Produção); Economia (25); Administração e Contabilidade (19) e outras sete áreas - proporção próxima àquelas já apresentadas.

Um ponto considerado relevante foi apurar se a dissertação e/ou a tese do DEAMISTA empregava a DEA. Dos 91 casos, 31 aplicaram a DEA na titulação (1 a cada 3 pesquisadores), tão mais relevante por se considerar que 1 a cada 3 DEAMISTAS se titulou antes de 1995, ano considerado como de início da difusão da DEA no País. Essa indicação foi considerada suficiente para se abrir outra investigação, procurando representar o mecanismo de difusão do instrumento via orientação de pós-graduação, discorrida em item destacado. Antes, é oportuno ressaltar que o BD.II incorporou 2 dissertações e 2 teses que não tinham sido ainda recuperadas quando da constituição do BD.I.

Outro resultado diz respeito ao modelo de ajuste cúbico que, novamente, foi aquele que melhor representou a curva de frequência amortizada do ano de publicação do primeiro trabalho (dito, momento do contágio) de cada pesquisador, em função das informações contidas no BD.I (cabe ressaltar que o contágio pode ter ocorrido em data anterior à 
DINÂMICA DA ASSIMILAÇÃO DE MÉTODOS ANALÍTICOS PELA CIÊNCIA NO

\section{BRASIL}

encontrada na amostra - então, o ponto considerado representa aquele mais tarde admissível). A estatística do modelo apresenta $\mathrm{R}^{2}=1,000$; Erro padrão da estimativa =0,003 e sig. 0,000. A Figura 2 representa tal estatística.

A curva da Figura 2 é diferente da curva logística (curva em "S") esperada para um modelo de difusão dependente da rede de relacionamentos. Haveria duas explicações concorrentes para essa divergência: (a) e (b), em que (a) a difusão não depende da rede de relacionamentos; e (b) o processo ainda estaria na fase que antecede a curvatura superior do S (ainda haveria uma fração considerável de pesquisadores aptos a adotarem a DEA e o instrumento não teria, por enquanto, saturado os periódicos ou os programas de pósgraduação). A possibilidade (a) pode ser contestada com a evidência do papel relevante das relações de orientação na estruturação da rede, discorrida a seguir.

Figura 2 - Ano de contágio

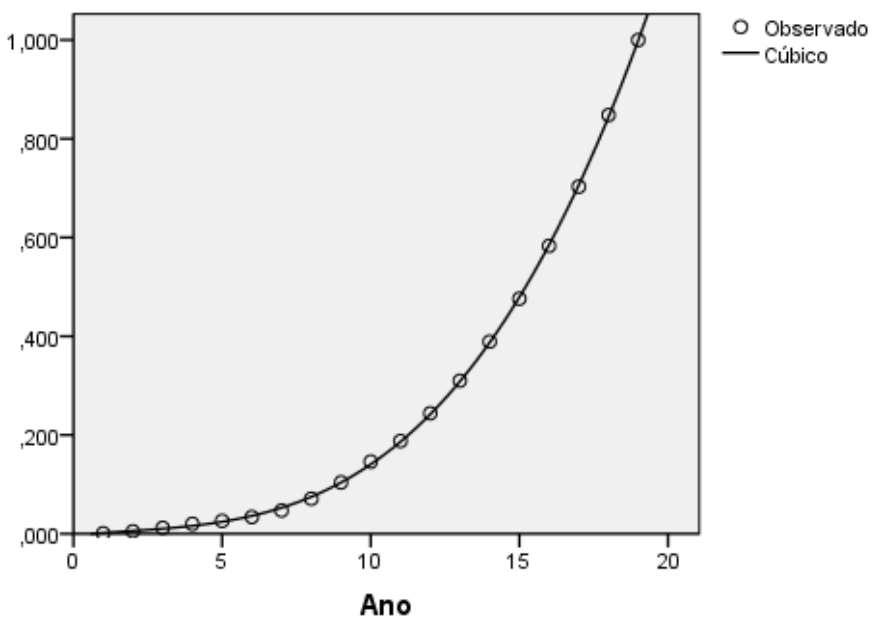

Fonte: dados da pesquisa

Nota: Ano 0 considerado $=1995$.

A questão foi investigada a partir da constatação de que uma fração considerável de pesquisadores usou a DEA em sua dissertação e/ou tese, com o orientador e o orientando formando ligações, que resultaram em rede.

Para efeito de demonstração, elegeu-se um elo fundamental da rede. A escolha recaiu sobre MPE LINS (orientador mais frequente entre os DEAMISTAS), desenrolando-a a partir daí (salientando: apenas entre os DEAMISTAS). A Figura 3 apresenta o resultado, em que D e T, à esquerda das caixas, são, respectivamente, Dissertação e Tese (a primeira que ocorrer), o nome ao centro das caixas indica o orientando ou o orientador, conforme o caso; e os 
Uajará Pessoa Araújo, Laíse Ferraz Correia, Mozar José de Brito \& Hudson Fernandes Amaral

números à direita indicam a quantidade de trabalhos com a participação do pesquisador. Por fim, o ano refere-se à data da defesa do trabalho.

Figura 3 - linha de tempo das orientações a partir do trabalho de LINS

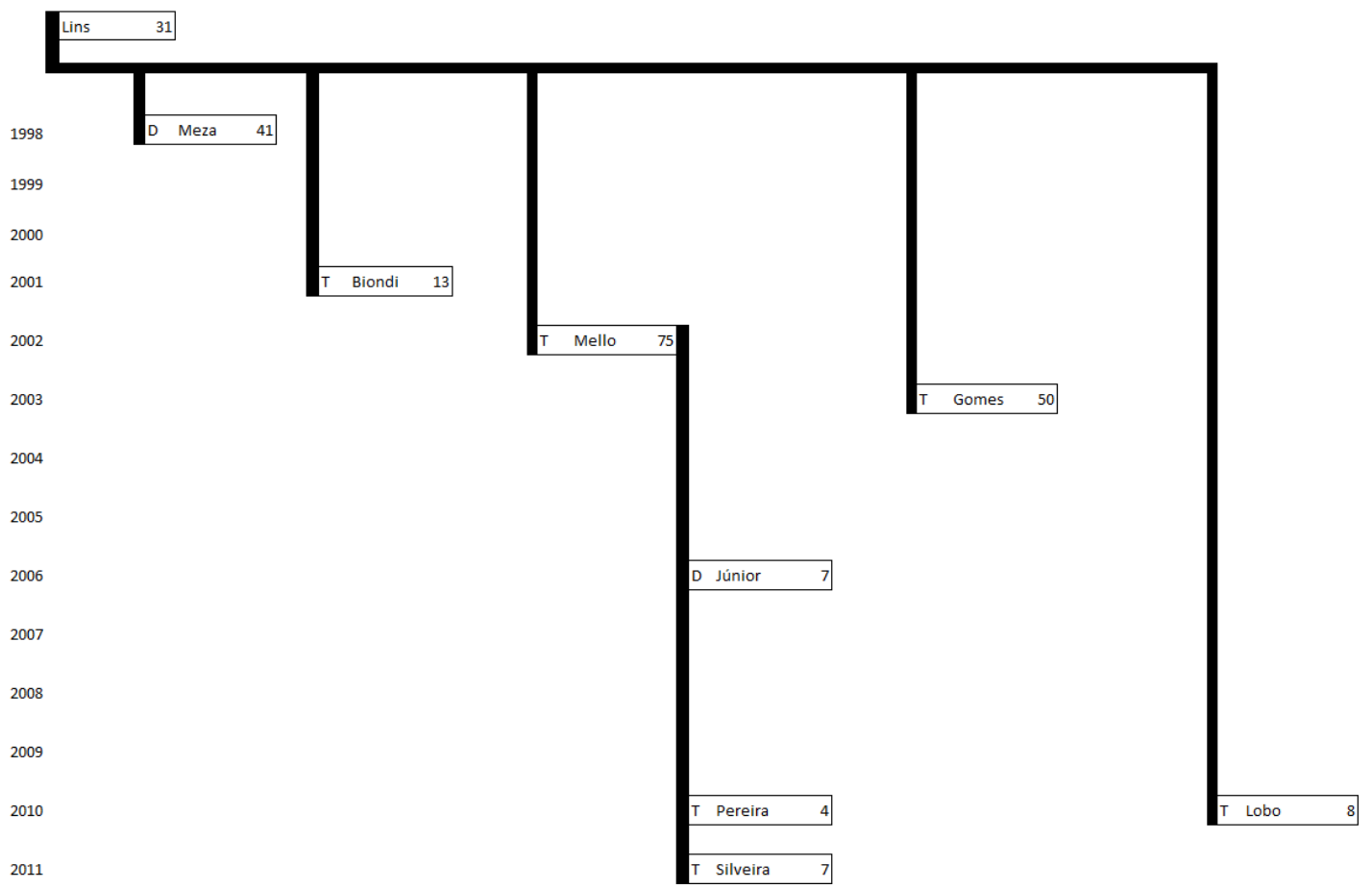

Fonte: dados da pesquisa

A Figura 3 torna evidente a germinação de um núcleo de DEA, por sinal, incorporando 5 dos 6 maiores DEAMISTAS, irradiado por ligações orientando-orientador, que persiste ao longo do tempo. O grupo é denso, coeso e estável, ainda que não mais centralizado no pioneiro (LINS) e sim em elementos da segunda Geração de DEAMISTAS, e configura-se na forma do sociograma apresentado na Figura 4, gerado a partir dos dados do BD.I.

Figura 4 - Rede de relações de orientação de DEAMISTA a partir de Lins

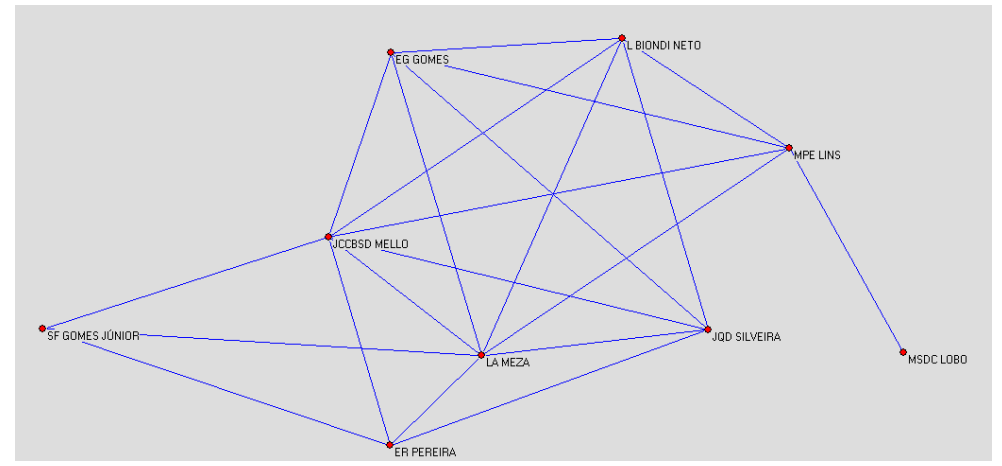

Fonte: dados de pesquisa 
DINÂMICA DA ASSIMILAÇÃO DE MÉTODOS ANALÍTICOS PELA CIÊNCIA NO

\section{BRASIL}

O grupo descrito na Figura 3 é o centro da parte inferior do maior componente ilustrado à esquerda na Figura 5. Essa Figura mostra, parcialmente (apenas os componentes maiores), a estrutura das ligações dos Deamistas no País. São 1.129 pesquisadores que responderam por 803 trabalhos (teses, dissertações e artigos) desde 1995 até o momento da coleta de dados, com 2.111 participações (média de 2,6 autores por trabalho) e 3.219 pares de ligações. A média é de 2,849 ligações por pesquisador (Degree), que resultou em um arranjo pouco denso (densidade $=0,003$ ), fragmentado (índice de fragmentação 0,931), desconectado (índice de conectividade de 0,069) de 214 componentes (alguns, não mais do que pesquisadores isolados e pares de pesquisadores, outros com dezenas deles), tendo o maior o diâmetro de 12 .

Figura 5 - Rede de Deamistas

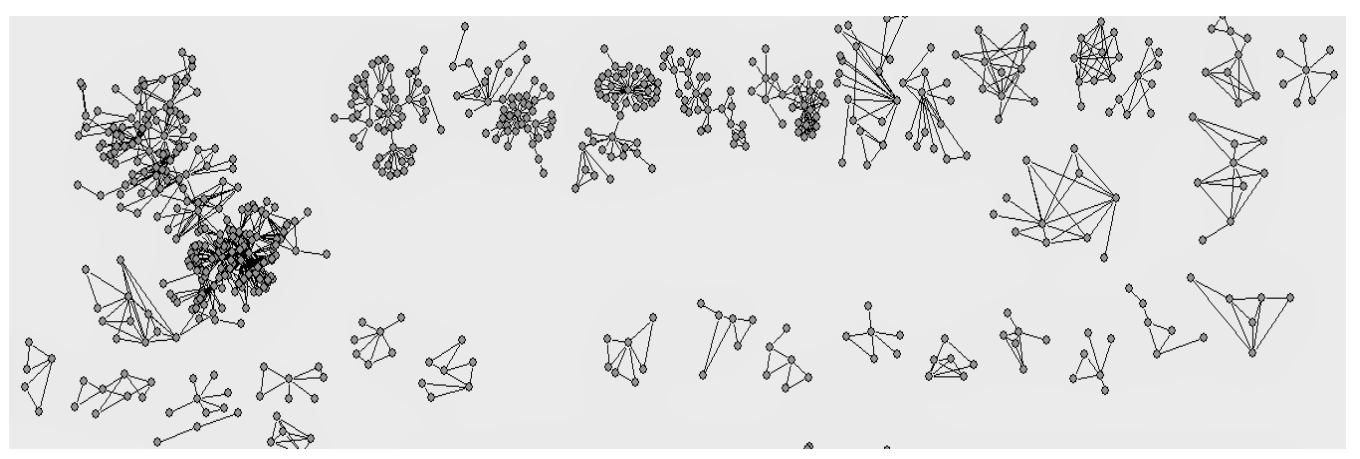

Fonte: dados da pesquisa

Aplicando um foco nos componentes maiores é possível visualizar que se tratam de arranjos centralizados em um pesquisador ou em um grupo desses, com a notável exceção do componente maior. Esse possui dois pontos de centralização, acima e abaixo (nesse último, centralizado nos elementos presentes na Figura 3), como se fossem duas subredes conectadas por alguns pesquisadores (bridges) que participam das duas partes.

Cabe um reparo: é razoável admitir que essas pontes também podem existir entre os demais componentes, porém não teriam sido evidenciados (como algum trabalho publicado, mas não recuperado na pesquisa ou a situação de alguns pesquisadores gozarem de outro tipo de ligação relacionada à DEA, além da publicação conjunta). A leitura dessa limitação implica aceitar a conectividade quando o laço está presente e não refutar essa possibilidade, quando os componentes não apresentam ligações entre si.

O cluster cultivado inicialmente por MPE LINS é a evidência mais exemplar da existência de um mecanismo de difusão sustentado por ligações fortes e pela dependência de recursos, em paralelo ao mecanismo de ligações fracas, antecipado por Granovetter (1973). 
Uajará Pessoa Araújo, Laíse Ferraz Correia, Mozar José de Brito \& Hudson Fernandes Amaral

Pelo mecanismo de ligações fracas, a difusão poderia se dar quando um pesquisador: recebe impulso ao ler uma peça produzida por seus pares; investiga e percebe que outros já estão adotando o instrumento (esse conjunto deveria compor a rede de citações); verifica que o instrumento é compatível com seus interesses (objetos de pesquisa) e que há espaço para publicação, visto a aceitação de trabalhos assemelhados; produz a sua pesquisa; e externaliza a sua rede de referências. O seu trabalho passa a se alinhar aos anteriores para "contaminar" outro pesquisador. Seria como uma gripe, em que bastaria estar em um ambiente contaminado para ser "apanhado" por ela.

Pelas ligações fortes, um orientador estimula (ou mesmo determina) seu grupo de orientandos a resolver a questão de pesquisa relativa à eficiência (área de interesse do orientador, aceita pelo orientando) usando a técnica, o que facilita o aprendizado da DEA. A pesquisa é desenvolvida e publicada, com a coautoria do orientador (que assim reforça a sua posição de liderança no campo). O orientado se torna um expert e busca meios de extrair o máximo de valor do instrumento. Ele busca atrair parceiros que ainda não dominam o instrumento, mas que conhecem os parâmetros (input e output, requeridos para a DEA) e sabem interpretar os resultados. O Parceiro e o ex-orientado trabalham juntos, em alguns casos, ainda sob a supervisão do orientador, e publicam a pesquisa. O Parceiro e o exorientado, ambos agora especialistas, procuram novos parceiros e o contágio se perpetua, ainda mais quando um ou outro (senão ambos), catapultados pela pesquisa, tornam-se também orientadores. Aqui, a relação precisa de um contato próximo (algumas vezes, prolongado pela duração da pesquisa), assemelhado a uma infecção transmitida por contato íntimo e frequente, e a DEA cumpre seu designo de reviver a cada publicação.

Uma explicação para as ligações fortes pode ser o esforço (e risco) demandado para o aprendizado. Quanto maior o esforço inferido - e assim, dependendo da proximidade da técnica com o cabedal de conhecimento que o pesquisador detenha -, menor a probabilidade de haver o contágio apenas pela leitura de algo, mesmo que isso tenha se espraiado. $\mathrm{O}$ orientador reduz o esforço (ao facilitar meios de aprendizado) e desvanece em alguma escala o risco de rejeição da pesquisa, pela sua posição e respaldo acadêmico de professor. Uma vez aprendida, é razoável admitir que, quanto maior for o investimento realizado, maior a propensão de se buscar uma compensação utilizando a técnica, o que é facilitado quando o instrumento tem aplicação multidisciplinar, como a DEA. O novo parceiro pode ser um engenheiro, um médico ou mesmo um zootecnista. Talvez, o especialista em DEA não precise procurá-lo: é razoável que o parceiro potencial procure o Deamista (tanto mais provável quanto maior for a reputação gozada pelo especialista, sempre propenso a ampliá-la), atrás do 
DINÂMICA DA ASSIMILAÇÃO DE MÉTODOS ANALÍTICOS PELA CIÊNCIA NO BRASIL

conhecimento. De uma ou de outra forma, a pesquisa acontece e se publica em um periódico com múltipla qualificação Qualis para beneficiar a ambos.

Um tipo de ligação não excluiria o outro (o sociograma da Figura 5, se completo, compreenderia 213 outros componentes, além daquele de MPE LINS), cada um com a sua história) e não seria improvável a conjunção dos dois mecanismos (forte e fraco), propelindo o pesquisador a adotar a DEA.

Por fim, como complemento da análise, foram construídos os sociogramas e apuradas as características do arranjo de Deamistas ao longo do tempo, acumulando-se os dados de 1995 a 1997 e, a partir daí, anualmente, até 2014, no momento da coleta de dados, incluindo: número de vértices; número de ligações distintas entre os vértices; degree médio; densidade; fragmentação; conectividade; número de componentes; e diâmetro do maior componente.

Os dados sugerem que os Deamistas estão, desde as primeiras iniciativas, distribuídos em estruturas desconectadas entre si, afastando-se a noção da existência de uma rede inteiriça, mesmo em algum momento. Mas o inventário de componentes de maior extensão e de maior coesão interna é crescente, como inferido pela combinação do aumento: do número médio de pesquisadores por componente, do degree médio e do diâmetro do componente maior mesmo com a redução da densidade de ligações.

\section{CONCLUSÕES}

A Sociometria, a DEA e outros instrumentos de apoio à decisão foram absorvidos no Brasil e aplicados a múltiplas situações. Ao final, as evidências vão no sentido de indicar que há um atraso variável na adoção de técnicas de pesquisas americanas. Também foi possível constatar que, no que concerne aos instrumentos de apoio à decisão considerados, assim como à Sociometria, eles se encontram em algum ponto na curva de difusão, após a fase de nucleação e antes da fase de redução do número de novas publicações (isso, se, em algum momento, o modelo cúbico encontrado for substituído pelo modelo logístico, com a saturação do campo. Em complemento, pelo aspecto das curvas e de acordo com a experiência americana, pode-se afirmar que não há evidência de que a saturação do campo venha acontecer nos próximos três anos.

Isso implica dizer que, se alguém pretende aprender a DEA e aplicá-la, deve encontrar aceitação da publicação no horizonte de tempo razoável e que esses entrantes mais tardios devem procurar valorizar o trabalho, compensando o esvaziamento provocado pela perda de 
Uajará Pessoa Araújo, Laíse Ferraz Correia, Mozar José de Brito \& Hudson Fernandes Amaral

novidade da DEA (o instrumento já seria atualmente menos importante que o objeto e o resultado da pesquisa).

Outro ponto relevante faz oposição ao modelo que prevê o contágio persistente (que só cessaria quando todos potencialmente passíveis de contaminação estivessem infectados), pois seria possível que a população remanescente crie mecanismos "de defesa": apesar de se ter notícia do instrumento, não busca conhecê-lo (tão menos, aplicá-lo) por esse haver perdido a novidade; em paralelo, pela eventual introdução de outro instrumento de mesmo propósito, porém mais inovador.

Assim como outros trabalhos do gênero, a distribuição de frequência - muitos com pouco, poucos com muito - foi encontrada em diversos aspectos analisados como a produção por pesquisador, a pontuação Qualis por pesquisador, as publicações por periódicos, a produção por programa de pós-graduação e a produção por campo de pesquisa. Os dados não levaram à rejeição da "Lei” de Lotka.

A opção por estudar as ligações via coautoria, em vez de citações, mostrou-se reveladora. Usar citação conduziria a um viés, uma vez que as publicações nacionais exigem artigos recentes e internacionais para representar o estado da arte. Adicionalmente, enquanto uma relação de coautoria implica uma relação mais fática, apontar um artigo em um trabalho não representa um atestado de que aquele artigo motivou a adoção do procedimento. $\mathrm{O}$ artigo pode estar ali mais para assegurar uma fundamentação (e facilitar a publicação), do que demonstrar uma deferência pelo papel do artigo citado na concepção da pesquisa. É razoável que a contaminação tenha se dado em um curso ou seminário, considerados como fonte de segunda linha, que sequer é noticiado na peça publicada.

Adicionalmente, aponta-se que o papel das ligações fortes tem sido negligenciado na explicação da difusão. Isso devido ao emprego preponderante das citações como indicativo de ligações e por não se trabalhar com teses e dissertações.

Digna de apreciação é a eficiência conseguida pelo núcleo ao redor de MPE LINS. Se o investimento em tempo no aprendizado e na aplicação da DEA fosse considerado como input e a pontuação Qualis como output em uma DEA, eles se constituiriam na fronteira de produção, impondo um pesado distanciamento aos pesquisadores menos eficientes.

Outro ponto revelador é que um programa de pós-graduação pode alavancar a produção ao se especializar em uma nova técnica em seu nascedouro (ainda mais se a técnica tiver aplicação multidisciplinar), conquanto essa técnica tenha aceitação persistente pela comunidade científica. Essa estratégia pode ser motivo de críticas negativas (como 
DINÂMICA DA ASSIMILAÇÃO DE MÉTODOS ANALÍTICOS PELA CIÊNCIA NO

\section{BRASIL}

"produtivismo"), mas para o corpo da Ciência (e qualquer outra área) a especialização, desde Adam Smith, tem sido aceita como uma ferramenta de aumento da produtividade.

Salienta-se também que a variável geográfica ainda cumpre papel significativo na explicação de ligações entre pesquisadores, conforme demostrado pela concentração da aplicação da DEA em algumas instituições. Não haveria a necessidade de empregar esforços para atrair um pesquisador distante (a menos de se impregnar na reputação deste) se o conhecimento necessário está ali, a uma mesa de distância.

Finalizando, sugere-se que a Coordenação de Aperfeiçoamento de Pessoal de Nível Superior (Capes), as comissões editoriais de periódicos e os colegiados dos cursos de pósgraduação levem em consideração esses resultados e suas implicações quando pretenderem implementar alguma mudança no meio científico.

Um estudo sociométrico sofre algumas restrições, que requerem a sua explicitação. Primeiro a qualidade da amostra. Quase sempre a definição de tamanho e o repositório usado como fonte para recuperação dos registros recebe a discricionariedade dos responsáveis, que agem por conveniência. Esse também foi o caso aqui. Para remediar a situação, seguiu-se de forma rigorosa os procedimentos apresentados na seção 2. Outro ponto, comum a outros estudos, é limitar a definição de ligações a um único tipo. Porquanto, ressalta-se aqui que uma linha no sociograma é indicativo de uma ligação, a ausência dela não implica dizer que não haja outro tipo de conexão.

Para complementar o quadro comparativo, seria interessante aprofundar o estudo da difusão de outros instrumentos de apoio à decisão apresentados neste texto e também a Sociometria. Há uma pretensão dos autores deste artigo em perseguir a trajetória desses itens ao longo de sua disseminação na academia de pesquisa brasileira.

\section{REFERÊNCIAS}

ALVARADO, R.U. A lei de Lotka na bibliometria brasileira. Ciência da Informação, v.31, n.2, p.14-20, 2002.

BETTENCOURT, L.M.A. The power of a good idea. Physica A, v.364, p.513-536, 2006.

CHARNES, A; COOPER, W.W.; RHODES, E. Measuring the efficiency of decision making units. European Journal of Operational Research, v.2, p.429-444, 1978.

DELRE, S.A. Will It spread or not? Journal of Product Innovation Management, v.27, p.267-282, 2010. 
Uajará Pessoa Araújo, Laíse Ferraz Correia, Mozar José de Brito \& Hudson Fernandes Amaral

GAO, X.; GUAN, J. Network model of knowledge diffusion. Scientometrics, v.90, p.749$762,2012$.

GLÄNZEL, W. Coauthorship patterns and trends in the science. Library Trends, v.50, n.3, p.461-473, 2002.

GRANOVETTER, M. The strength of weak ties. American Journal of Sociology, v.78, n. 6, p.1360-1380, 1973.

HALKOS, G.E.; TZEREMES, N.G. Measuring economic journals' citation efficiency.

Scientometrics, v.88, p.979-1001, 2011.

HO, M.H-C.; LIU, J.S. The motivations for knowledge transfer across borders.

Scientometrics, v.94, n.1, p.397-421, 2013.

KATZ, E. Studies of innovation and of communication to the public. Stanford: Stanford University, 1961.

KORTELAINEN, T.A.M. Applying concepts of diffusion research in an informetric study. Scientometrics, v.40, n.3, p.555-568, 1997.

LOTKA, A.J. The frequency distribuition of scientific productivity. Journal of the Washington Academy of Science, v.16, n.12, p.317-323, 1926.

MACEDO, M.A.S.; CASANOVA, S.P.C.; ALMEIDA, K. Mapeamento e análise bibliométrica da utilização da Análise Envoltória de Dados. Contabilidade, Gestão e Governança, v.12, n.3, p.87-101, 2009.

MONTANARI, A.; SABERI, A. The spread of innovations in social networks. PNAS, v.107, n.47, p.20196-20201, 2010.

NASCIMENTO, S. Investigação da produção científica. Revista de Contabilidade do Mestrado em Ciências Contábeis da UERJ, v.15, n.3, p.78-92, 2010.

ROGERS, E.M. Diffusion of innovations. London: The Free Press, 1983.

ROUSSEAU, S.; ROUSSEAU, R. Data Envelopment Analysis as a tool for constructing scientometric indicators. Scientometric s, v.40, n.1, p.45-46, 1997.

SHARMA, S.; THOMAS, V. J. Inter-country R\&D efficiency analysis. Scientometrics, v.76, n.3, p.483-501, 2008.

SRIWANNAWIT, P.; SANDSTRÖM, Ulf. Large-scale bibliometric review of diffunion research. Scientometrics, v.[], p.[], 2014.

TONTA, Y; DARVISH, H.R. Diffusion of latent semantic analysis as a research tool. Journal of Informetrics, v.4, n.2, p.166-174, 2010.

TRAVERS, J.; MILGRAM, S. An experimental study of the small world problem. Psychology Today, v.2, p.60-67, 1967. 
DINÂMICA DA ASSIMILAÇÃO DE MÉTODOS ANALÍTICOS PELA CIÊNCIA NO BRASIL

YU, G.; WANG, M.-Y.;YU, D.-R. Characterizing knowledge diffusion of Nanoscience \& Nanotechnology by citation analysis. Scientometrics, v.84, p.81-97, 2010. 